\title{
8-METHOXYNEORAUTENOL AND RADICAL SCAVENGING FLAVONOIDS FROM ERYTHRINA ABYSSINICA
}

\author{
Abiy Yenesew ${ }^{1 *}$, Hannington Twinomuhwezi ${ }^{1,2}$, Bernard T. Kiremire ${ }^{2}$, Martin N. Mbugua ${ }^{1}$, \\ Peter M. Gitu ${ }^{1}$, Matthias Heydenreich ${ }^{3}$, Martin G. Peter ${ }^{3}$ \\ ${ }^{1}$ Department of Chemistry, University of Nairobi, P.O. Box 30197, Code 00100, Nairobi, Kenya \\ ${ }^{2}$ Department of Chemistry, Makerere University, P.O. Box 7062 Kampala, Uganda \\ ${ }^{3}$ Institut für Chemie, Universität Potsdam, P.O. Box 6015 53, D-14415 Potsdam, Germany
}

(Received September 13, 2008; revised February 10)

\begin{abstract}
A new pterocarpan (named 8-methoxyneorautenol) was isolated from the acetone extract of the root bark of Erythrina abyssinica. In addition, the known isoflavonoid derivatives eryvarin L, erycristagallin and shinpterocarpin were identified for the first time from the roots of this plant. The structures were determined on the basis of spectroscopic evidence. The new compound showed selective antimicrobial activity against Trichophyton mentagrophytes. The acetone extract of the root bark of E. abyssinica showed radical scavenging activity towards 2,2-diphenyl-1-picrylhydrazyl radical (DPPH). The pterocarpenes, 3-hydroxy-9-methoxy-10-(3,3dimethylallyl)pterocarpene and erycristagallin, were the most active constituents of the roots of this plant and showing dose-dependent activities similar to that of the standard quercetin.
\end{abstract}

KEY WORDS: Erythrina abyssinica, Root bark, Leguminosae, Pterocarpan, 8-Methoxyneorautenol, Pterocarpenes, 3-Hydroxy-9-methoxy-10-(3,3-dimethylallyl)pterocarpene, Erycristagallin, Antimicrobial, Radical scavengers, DPPH

\section{INTRODUCTION}

Erythrina abyssinica (Leguminosae) is distributed in warm regions of southern Africa and the savannah of eastern Africa [1]. It is used in traditional medicine for treatment of malaria, elephantiasis, trachoma and syphilis [2]. Previous phytochemical studies on E. abyssinica have shown that the plant elaborates alkaloids [1], flavanones, pterocarpans, chalcones and isoflavonoids [1, 3]; some of which have been shown to have antimicrobial [2, 4], antiplasmodial $[5,6]$ and inhibitory effects on protein tyrosine phosphatase 1B (PTP1B) [3] activities. In this paper, we report on the isolation and structure elucidation of a new pterocarpan, along with known isoflavonoid derivatives. The radical scavenging activities of the acetone extracts of the roots and stem bark of Erythrina abyssinica, and some of the compounds isolated from these extracts are also reported.

\section{RESULTS AND DISCUSSION}

The HRMS analysis of compound 1 showed $[\mathrm{M}+1]^{+}$peak at $\mathrm{m} / z, 353.1397$ corresponding to the molecular formula of $\mathrm{C}_{21} \mathrm{H}_{20} \mathrm{O}_{5}$. The ${ }^{1} \mathrm{H}$ and ${ }^{13} \mathrm{C}$ NMR spectra (Table 1) showed this compound to be a pterocarpan derivative. Furthermore the presence of hydroxyl, methoxyl and a 2,2dimethylpyran functionalities was established from NMR and MS data. In the A ring, the presence of two singlet aromatic protons at $\delta 7.12$ (for $\mathrm{H}-1$ ) and $\delta 6.37$ (for $\mathrm{H}-4$ ) requires that C-2 and C-3 are substituted. The HMBC correlation of one of the olefinic protons $(\mathrm{H}-4)$ of the 2,2-dimethylpyran functionalities with $\mathrm{C}-1$ is consistent with this group being at $\mathrm{C}-2 / \mathrm{C}-3$ with the expected oxygenation at C-3.

*Corresponding author. E-mail: ayenesew@uonbi.ac.ke 
Table 1. ${ }^{1} \mathrm{H}(500 \mathrm{MHz})$ and ${ }^{13} \mathrm{C}$ NMR $(125 \mathrm{MHz})$ data along with $\mathrm{HMBC}$ correlations in $\mathbf{1}\left(\mathrm{CDCl}_{3}\right)$.

\begin{tabular}{|c|c|c|c|}
\hline \multirow[t]{2}{*}{ Position } & \multicolumn{2}{|r|}{1} & \multirow[b]{2}{*}{$\operatorname{HMBC}\left({ }^{2} J,{ }^{3} J\right)$} \\
\hline & $\delta_{\mathrm{C}}$ & $\delta_{\mathrm{H}}(J$ in $\mathrm{Hz})$ & \\
\hline 1 & 128.3 & $7.12 \mathrm{~s}$ & C-3, 4a, 11a, 4' \\
\hline 2 & 116.4 & & \\
\hline 3 & 154.6 & & \\
\hline 4 & 104.7 & $6.37 \mathrm{~s}$ & $\mathrm{C}-2,3,4 \mathrm{a}$ \\
\hline $4 a$ & 156.2 & & \\
\hline 6 & 66.5 & 3.62 dd $(-10.9,11.3)$ & C-6a, \\
\hline & & $4.22 \mathrm{dd}(5.1,-10.9)$ & C-4a. 6a. 11a \\
\hline $6 a$ & 40.3 & 3. 49 ddd $(5.1,6.4,11.3)$ & $\mathrm{C}-6,11 \mathrm{a}$ \\
\hline $6 b$ & 116.9 & & \\
\hline 7 & 107.8 & $6.79 \mathrm{~s}$ & C-6a, $8,9,10 \mathrm{a}$ \\
\hline 8 & 141.1 & & \\
\hline 9 & 146.6 & & \\
\hline 10 & 98.1 & $6.51 \mathrm{~s}$ & $C-8,9,10 a, 6 b$ \\
\hline $10 \mathrm{a}$ & 153.9 & & \\
\hline $11 \mathrm{a}$ & 78.2 & $5.42 \mathrm{~d}(6.4)$ & $C-1,4 a, 6$ \\
\hline $11 b$ & 112.4 & & \\
\hline $2^{\prime}$ & 76.6 & & \\
\hline $3^{\prime}$ & 129.1 & $5.54 \mathrm{~d}((9.8)$ & C- $2,2^{\prime}$ \\
\hline $\begin{array}{l}4^{\prime} \\
2^{\prime}\left(\mathrm{CH}_{3}\right)_{2}\end{array}$ & $\begin{array}{l}121.6 \\
27.9\end{array}$ & $\begin{array}{l}6.31 \mathrm{~d}(9.8) \\
1.40 \mathrm{~s}\end{array}$ & $\mathrm{C}-1,3,2^{\prime}$ \\
\hline & 28.2 & $1.43 \mathrm{~s}$ & \\
\hline $8-\mathrm{OCH}_{3}$ & 57.0 & 3.86 & $\mathrm{C}-8$ \\
\hline
\end{tabular}

In the D-ring the presence of two para-oriented aromatic protons at $\delta 6.79(\mathrm{H}-7)$ and 6.51 (H-10) and the chemical shift values of the aromatic carbon atoms, $\delta 116.9$ (C-6b), $107.8(\mathrm{C}-7)$, 141.1 (C-8), 146.6 (C-9), 98.1 (C-10) and 153.9 (C-10a) require that the methoxyl and the hydroxyl groups are substituted at C-8 and C-9, respectively. The position of the methoxyl group was fixed at C-8 rather than C-9, from NOEDIFF experiment; where irradiation of the methoxyl group showed NOE interaction on H-7 $(\delta$ 6.79). This was confirmed through the HMBC correlation between the methoxyl protons and C-8, and also between $\mathrm{H}-7$ and $\mathrm{C}-8$ (Table 1). This compound was therefore assigned structure $\mathbf{1}$ for which the trivial name 8methoxyneorautenol was suggested. The high negative optical rotation $\left([\alpha]_{D^{-}}-246.6^{\circ}\right)$ is consistent with $6 \mathrm{a} R: 11 \mathrm{a} R$ configuration in this compound [7].

In addition, the pterocarpan shinpterocarpin $[8,9]$ and the arylbenzofuran eryvarin $L(2)$ have been identified from the roots of this plant for the first time. Compound $\mathbf{2}$ is rare and has only been reported from the twigs of E. abyssinica [1] and the roots of E. varigata [10]. It is worth noting that this compound co-occurs in E. varigata with the isoflav-3-ene eryvarin $\mathrm{H}(3)$ which has identical oxygenation pattern as compound 2 [10]. It has been proposed that eryvarin $\mathrm{L}$ is derived from eryvarin $\mathrm{H}$ in this plant [11]. These compounds also co-occur in E. abyssinca [5], supporting the biogenetic relationship between arylbenzofurans and isoflav-3-enes. The arylbenzofuran burttinol D co-occurs with the isoflav-3-ene burttinol $\mathrm{A}$ in the roots of $E$. burttii [12], and similar biogenetic relationship has been suggested for these compounds [11].

Compound 1 showed selective but weak antimicrobial activity against Trichophyton mentagrophytes with MIC value of $45 \mu \mathrm{g} / \mathrm{mL}$ [4], while it was inactive against a range of microorganisms [vis a vis Staphylococous aureus (ATCC 25923), Methicillin resistant Staphylococcus aureus (clinical isolate), Escherichia coli (ATCC 25922), Pseudomonas aeruginosa (ATCC 27853), Candida albicans (ATCC 90028), Trichophyton mentagrophytes, Cryptococcus neoformans (ATCC 66031) and Microsporum gypseum (clinical isolate)].

Preliminary tests for radical scavenging activities (RSA), using 2,2-diphenyl-1picrylhydrazyl (DPPH) free radical as a spray reagent on TLC plates, of the crude acetone 
extract of the root bark and the stem bark of E. abyssinica indicated the presence of active compounds. Using the spectrophotometric method, the RSA of the crude extracts were determined and both extracts showed potent activities $\left(\mathrm{EC}_{50}=7.7\right.$ and $17.4 \mu \mathrm{g} / \mathrm{mL}$ for root bark and stem bark extracts, respectively).

Some of the compounds previously isolated from the root bark [5] and the stem bark [6] of E. abyssinica were tested. Activities were observed among flavanones, pterocarpenes and isoflav-3-enes (Table 2). Among these isolates, the pterocarpenes erycristagallin (4) and 3hydroxy-9-methoxy-10-(3,3-dimethylallyl)pterocarpene (5) were identified as the most active principles in this plant. The activities of these pterocarpenes were tested at different concentrations (Figure 1) and both showed potent ( $\mathrm{EC}_{50} 8.2 \mu \mathrm{M}$ for $\mathbf{4}$ and $10.8 \mu \mathrm{M}$ for $\mathbf{5}$ ) and dose dependent radical scavenging activities towards DPPH, similar to that of the standard quercetin $\left(\mathrm{EC}_{50}\right.$ value $\left.5.4 \mu \mathrm{M}\right)$.

Table 2. Radical scavenging activities towards DPPH of compounds from E. abyssinica.

\begin{tabular}{|l|l|}
\hline Compound & $\mathrm{EC}_{50}(\mu \mathrm{M})$ \\
\hline Abyssinone IV & 32.4 \\
\hline Abyssinone V & 30.1 \\
\hline Abyssinin III & 21.7 \\
\hline $\mathbf{4}$ & 8.2 \\
\hline $\mathbf{5}$ & 10.8 \\
\hline 4',7-Dihydroxy-2',5'-dimethoxyisoflav-3-ene & 62.0 \\
\hline Quercetin & 5.4 \\
\hline
\end{tabular}

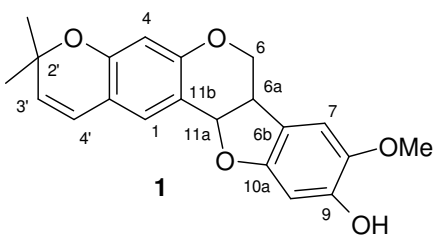<smiles>COc1cc(C2=Cc3ccc(O)cc3OC2)c(OC)cc1O</smiles>

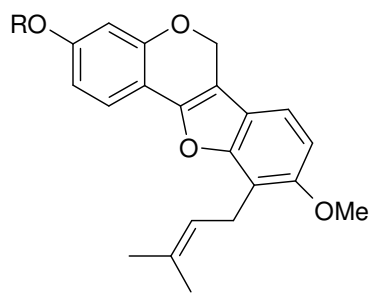

$5 \mathrm{R}=\mathrm{H}$

$5 a \quad R=A c$
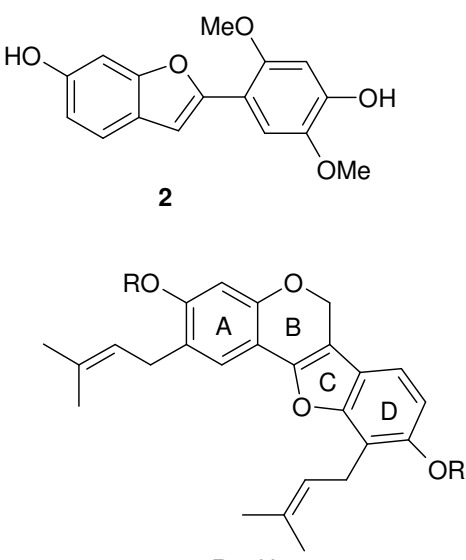

$4 \mathrm{R}=\mathrm{H}$

4a $\mathrm{R}=\mathrm{Ac}$

Bull. Chem. Soc. Ethiop. 2009, 23(2) 


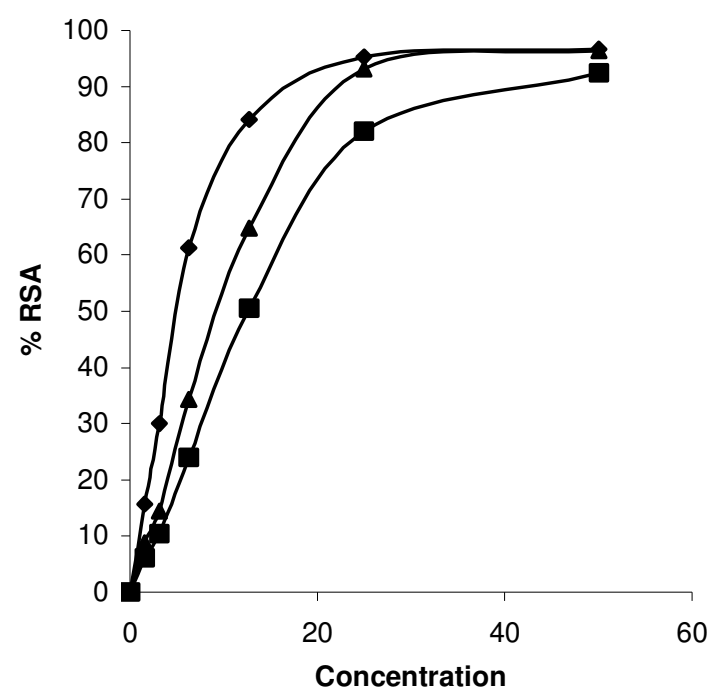

Figure 1. Radical scavenging activities (RSA) of different concentrations (in $\mu \mathrm{M}$ ) of $\mathbf{4}$ (घ) and $\mathbf{5}$ $(\boldsymbol{\Delta})$ together with quercetin $(\diamond)$ against DPPH.

As the standard quercetin, these pterocarpenes have free phenolic group(s) required for activity; and as expected [13], the acetate derivatives $\mathbf{4 a}$ and $\mathbf{5 a}$ were inactive even at $50 \mu \mathrm{M}$. The structural requirements for the high radical scavenging activity of quercetin and other related flavonoids has been reported to be due to the O-dihydroxyl structure in B-ring; the 2,3 double bond in conjunction with the 4-oxo function in the C-ring; and the 3- and 5-hydroxyl groups with hydrogen bonding to the keto group [14]. The structural features in the pterocarpenes, however, do not satisfy these requirements and yet these compounds showed very high radical scavenging activities. In both pterocarpenes where all four rings (A-, B-, Cand D-rings) are coplanar, and the double bond in C-ring appears to play an important role for the high radical scavenging activity, extending the conjugation among the four rings to stabilize the radical formed after loss of hydrogen to DPPH. The presence of 3,3-dimethylallyl group(s) in these pterocarpenes not only enhances the radical scavenging activities, but also increase the lipophilicity of these compounds and hence probably make them protect low density lipoproteins (LDL) better than the more polar flavonoids such as quercetin [13].

\section{EXPERIMENTAL}

\section{General}

Analytical TLC: Merck pre-coated silica gel $60 \mathrm{~F}_{254}$ plates. CC on oxalic acid impregnated silica gel 60 (70-230 mesh). EIMS: direct inlet, $70 \mathrm{eV}$, on a SSQ 710, Finnigan MAT mass spectrometer. HRMS were recorded with electrospray ionisation on a ESI-QTOFmicro mass spectrometer from Waters Inc. ${ }^{1} \mathrm{H}$ NMR (500 or $\left.200 \mathrm{MHz}\right)$ and ${ }^{13} \mathrm{C}$ NMR (125 or $50 \mathrm{MHz}$ ) were recored on Bruker or Varian-Mercury spectrometers using TMS as internal standard. HMQC and $\mathrm{HMBC}$ spectra were acquired using the standard Bruker software. 


\section{Plant material}

The stem bark and root bark of E. abyssinica were collected near Thika town, Kenya, in December 2006. The plant was identified at the University Herbarium, Botany Department, University of Nairobi, where a voucher specimen is deposited.

\section{Extraction and isolation}

Air-dried and ground root bark $(1.7 \mathrm{~kg})$ of E. abyssinica was extracted with acetone by cold percolation at $25^{\circ} \mathrm{C}$. Removal of the solvent under reduced pressure afforded a brown sticky extract $(109 \mathrm{~g})$. A $100 \mathrm{~g}$ portion of the extract was fractionated on oxalic acid-impregnated silica gel $(350 \mathrm{~g})$ eluting with $\mathrm{n}$-hexane containing increasing amounts of dichloromethane $(5,10,20$, $30,40,50,60,70,80,90$ and $100 \%$ ). The fractions eluted with $20 \%$ and $30 \% \mathrm{CH}_{2} \mathrm{Cl}_{2}$ were combined and further subjected to $\mathrm{CC}$ on oxalic acid-impregnated silica gel (eluting with $2 \%$ EtOAc in n-hexane) and purified on Sephadex LH-20 (eluted with $\mathrm{CH}_{2} \mathrm{Cl}_{2} / \mathrm{MeOH} ; 1: 1$ ) to give compound $1(9 \mathrm{mg})$. The fraction eluted with $50 \% \mathrm{CH}_{2} \mathrm{Cl}_{2}$ in hexane was purified on Sephadex LH-20 (eluted with $\mathrm{CH}_{2} \mathrm{Cl}_{2} / \mathrm{MeOH} ; 1: 1$ ) and then by preparative TLC (silica gel, hexane/ $\mathrm{CH}_{2} \mathrm{Cl}_{2}$, $3: 7)$ to give shinpterocarpin $(6 \mathrm{mg})$ and $\mathbf{4}(43 \mathrm{mg})$ and $\mathbf{5}(26 \mathrm{mg})$. The fraction eluting with $70 \%$ $\mathrm{CH}_{2} \mathrm{Cl}_{2}$ in $\mathrm{n}$-hexane was purified on a preparative TLC (n-hexane/ $\mathrm{CH}_{2} \mathrm{Cl}_{2}, 1: 4$ ) to give compound $2(7 \mathrm{mg})$.

\section{8-Methoxyneorautenol (1)}

Amorphous powder. $[\alpha]_{\mathrm{D}}-246.6^{\circ}(c 0.01, \mathrm{MeOH})$. UV $\lambda_{\max }(\mathrm{MeOH}): 283,234 \mathrm{~nm}$. IR $v_{\max }: 3580$, 2825, 1620, 1610, 1596, $1495 \mathrm{~cm}^{-1} .{ }^{1} \mathrm{H}$ NMR (Table 1). ${ }^{13} \mathrm{C}$ NMR (Table 1). ESI-HRMS $\mathrm{m} / \mathrm{z}$ $[\mathrm{M}+1]^{+} 353.1397 \mathrm{C}_{21} \mathrm{H}_{21} \mathrm{O}_{5}$. EIMS $m / z$ (rel. int.): $352\left(46,[\mathrm{M}]^{+}\right), 337[\mathrm{M}-\mathrm{Me}]^{+}(100)$.

Radical scavenging activity test using DPPH

To a methanolic solution $(3 \mathrm{~mL})$ of DPPH $(100 \mu \mathrm{M}), 0.5 \mathrm{~mL}$ of each of the test compound from a $50 \mu \mathrm{M}$ solution $(10 \mu \mathrm{g} / \mathrm{mL}$ for crude extract) were added and the mixture was shaken and left to stand for $30 \mathrm{~min}$. The radical scavenging activities were estimated as the percent decrease of the absorbance of DPPH $(100 \mu \mathrm{M})$ at $517 \mathrm{~nm}$ [15]. Tests were done at six different concentrations $(50,25,12.5,6.25,3.13$ and $1.56 \mu \mathrm{M})$. In all cases the mean values were used from triplicate experiments. $\mathrm{EC}_{50}$ values were calculated using Finney's probit analysis for quantal data [16].

\section{AKNOWLEDGEMENTS}

We acknowledge support by the Deutsche Forschungsgemeinschaft, Germany, Grant No. Pe 264/14-5 and by the Bundesministerium fuer Zusammenarbeit, Grant No. Pe-264/14-6. Mr S.G. Mathenge is thanked for identification of the plant material.

\section{REFERENCES}

1. Machumi, F.; Bojase-Moleta, G.; Mapitse, R.; Masesane, I.; Majinda, R.R.T. Nat. Prod. Commun. 2006, 1, 287.

2. Kamat, V.S.; Chou, F.Y.; Kubo, I.; Nakanishi, K. Heterocycles 1981, 15, 1163.

3. Cui, L.; Thuong, P.T.; Lee, H.S.; Ndinteh, D.T.; Mbafor, J.T.; Fomum, Z.T.; Oh, W.K. Bioorg. Med. Chem. 2008, 16, 10356. 
4. Yenesew, A.; Derese, S.; Midiwo, J.O.; Bii, C.C.; Heydenreich, M.; Peter, M.G. Fitoterapia 2005, 76, 469.

5. Yenesew, A.; Derese, S.; Irungu, B.; Midiwo, J.O.; Waters, N.C.; Liyala, P.; Akala, H.; Heydenreich, M.; Peter, M.G. Planta Med. 2003, 69, 658.

6. Yenesew, A.; Induli, M.; Derese, S.; Midiwo, J.O.; Heydenreich, M.; Peter, M.G.; Akala, H.; Wangui, J.; Liyala, P.; Waters, N.C. Phytochemistry 2004, 65, 3029.

7. Yenesew, A.; Midiwo, J.O.; Miessner, M.; Heydenreich, M.; Peter, M.G. Phytochemistry 1998, 48, 1439.

8. Yenesew, A.; Midiwo, J.O.; Heydenreich, M.; Peter, M.G. Phytochemistry 2000, 55, 457.

9. Kitagawa, I.; Chen, W.-Z.; Hori, K.; Harada, E.; Yasuda, N.; Yoshikawa, M.; Ren, J. Chem. Pharm. Bull. 1994, 42, 1056.

10. Tanaka, H.; Hirata, M.; Etoh, H.; Sako, M.; Sato, M.; Murata, J.; Murata, H.; Darnaedi, D.; Fukai, T. Heterocycles 2003, 60, 2767.

11. Veitch, N.C. Nat. Prod. Rep. 2007, 24, 417.

12. Yenesew, A.; Midiwo, J.O.; Guchu, S.M.; Heydenreich, M.; Peter, M.G. Phytochemistry 2002, 59, 337.

13. Belinky, P.; Aviram, M.; Mahmood, S.; Vaya, J. Free Radic. Biol. Med. 1998, 24, 1419.

14. Krishnamachari, V.; Levine, L.H.; Pare, P.W. J. Agric. Food Chem. 2002, $50,4357$.

15. Ohinishi, M.; Morishita, H.; Iwahashi, H.; Toda, S.; Shirataki, Y.; Kimura, M.; Kido, R. Phytochemistry 1994, 36, 579.

16. McLaughlin, J.R.; Chang, C-J.; Smith, D.L. "Bench-Top"Bioassays for Discovery of Bioactive Natural Products: an update in: Studies in Natural Products Chemistry, Atta-urRahman (Ed.), Elsevier: Amsterdam; 1991; 99, p 383. 